Journal of Thermal Engineering, Vol. 7, No. 2, Special Issue 13, pp. 240-255, February, 2021

Yildiz Technical University Press, Istanbul, Turkey

\title{
EFFECT OF DYE CONCENTRATION ON PATTERNED LUMINESCENT SOLAR CONCENTRATOR
}

\author{
G. Gopi ${ }^{1}$, T.J.S. Jothi ${ }^{1, *}$, S. Kumaravel ${ }^{2}$
}

\begin{abstract}
The present paper investigates the Luminescent Solar Concentrator (LSC) with single and dual waveguide coated with perylene dye of various concentrations. Monte Carlo simulations are carried out to assess the efficiency of the LSC with the waveguide areas varying from 10 to $110 \mathrm{~cm}^{2}$, and the dye concentration varying from 30 to $800 \mathrm{PPM}$. The percentage of dye area coated in the waveguides is varied from 20 to $80 \%$. Results indicate that the LSC efficiency increases with dye concentration up to a particular value, and thereafter shows a decreasing trend. Further, LSC efficiency is found to be increasing with a decrease in waveguide size. Experimental and simulation results indicate the maximum efficiency at the dye coverage area of 50\%. Simulation results indicate the maximum LSC efficiency of around $9 \%$, while the same is around $6 \%$ when examined experimentally.
\end{abstract}

Keywords: Patterned LSC, Perylene Dye, Monte-Carlo Simulation, Dual Waveguide, PV Cell

\section{INTRODUCTION}

Solar energy is the sustainable source of energy besides the other energy resources like oil, coal, natural gas, and biomass. It is understood that only a fraction of solar energy reaches the earth surface [1]. Harvesting solar energy can partly satisfy energy demands and thus overcome environmental problems. Photovoltaic (PV) cell is a solar device which converts solar radiation directly into electricity. Silicon is the most commonly used material for PV cells. PV cells are categorized as first, second, and third-generation depending upon the material and structure. First-generation PV is made of doped silicon while the second-generation uses thin-film technology. Third-generation PV utilizes the concept of multi-junction cells that are the most efficient cells developed with efficiencies above $40 \%$. In the recent past, commonly produced PV cells include polycrystalline silicon, amorphous silicon, and thin-film silicon.

Luminescent Solar Concentrator (LSC) is a solar device that works on the principle of internal reflection of light and concentrates at the edges. The PV panels are placed at these edges to produce power. The schematic of the LSC is shown in Fig. 1. The solar radiation passing through the transparent glass internally reflects, and finally concentrates at the PV faces. The transparent plate is further doped with a fluorescent material to improve the LSC efficiency. This absorbs maximum solar spectrum, and emits at longer wavelength depending upon the critical angle of the transparent plate, as given by Snell's law (Eq. 1).

$$
\theta_{c}=\sin ^{-1}\left[\frac{1}{n_{i}}\right]
$$

where $\theta_{c}$ is the critical angle and $n_{\mathrm{i}}$ is the refractive index of the fluorescent plate. If the emitted angle of light radiation is greater than the critical angle of the plate, the total internal reflections are directed towards the edge of the collector. Thus, a larger refractive index waveguide has a smaller critical angle leading to entrapment of more radiation being guided towards the edge of the LSC. Higher efficiencies are achieved by developing highly stable luminescent materials with no overlap in absorption and emission spectrum, and by improving the structure of a waveguide. The current work aims at the improvement of LSC efficiency using the patterned dye on the waveguide. The dye concentration and dye coverage area of the waveguide patterns are varied to study its effect on LSC efficiency. Monte Carlo simulation technique is adapted to determine the optimum requirement of a dye concentration for maximum

This paper was recommended for publication in revised form by Regional Editor Jaap Hoffmann

${ }^{1}$ Department of Mechanical Engineering, National Institute of Technology Calicut, Kerala 673601, India

${ }^{2}$ Department of Electrical Engineering, National Institute of Technology Calicut, Kerala 673601, India

*E-mail address: tjsjothi@ nitc.ac.in

Orcid id: 0000-0002-9674-9045, 0000-0002-3795-7768

Manuscript Received 8 April 2019, Accepted 2 September 2019 
LSC efficiency. Further, dual patterned waveguides are considered and compared with single pattern waveguide. Experiments are carried out with the waveguides to support these simulation results.

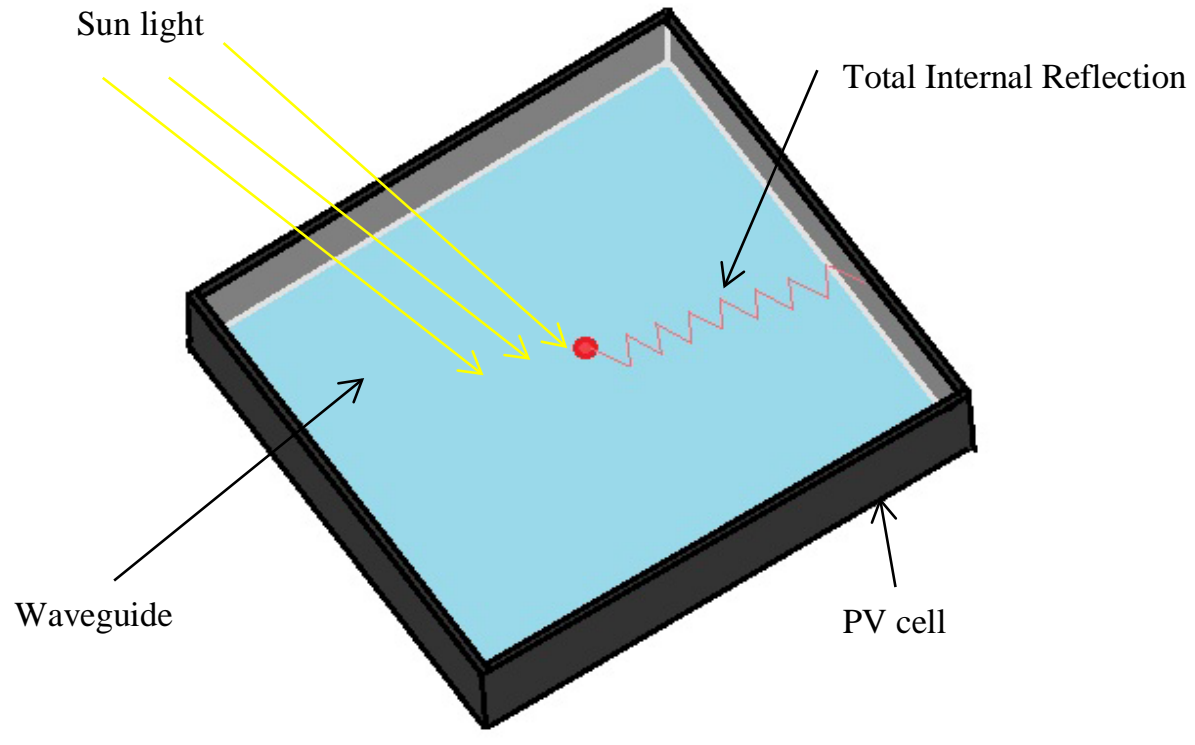

Figure 1. Schematic of luminescent solar concentrator

Numerous studies have been carried out in the field of LSC in terms of efficiency improvement, material usage, fluorescent dye material, and the number of waveguides. The operational and performance aspects of LSC are discussed by Batchelder et al. [2] by carrying theoretical and experimental analysis and compared their efficiencies. The cost per unit Watt is estimated to be lower than that of a planar silicon solar cell [3]. Friedman [4] analyzed the efficiencies of uniformly doped, stacked plate, thin-film, and multilayered film in LSCs. He found the maximum collector efficiency of 3.2\%. Slooff et al. [5] developed an LSC with $7.1 \%$ power conversion efficiency using GaAs PV cells for a collector having a geometrical concentration factor of 2.5. Debije et al. [6] have measured the surface losses and claimed the cone losses to be higher up to 40-50\% from the top and bottom surface of the LSC. Vishwanathan et al. [7] compared the flat and cylindrically bent LSC for their conversion efficiencies and observed that the latter performs well compared to the former in all weather conditions. Earp and co-workers [8,9] used the concept of LSC to transport the daylight to a remote part of a room where the sunshine is scarce and used to power the indoor environment. They have carried out simulations and measurements to see light transport in single and multicolored LSC. They used pink, green and violet dyes in LSCs and with PMMA guides to produce white light of $1000-1500 \mathrm{~lm}$. The optimization of the ray-tracing numerical model in LSCs using genetic algorithm is carried by Noyola et al. [10]. Using the sub-routines, optimal parameters such as losses due to wavelength shift and re-scattering are found. They suggested the theoretical limit for luminescent materials in terms of number layers for the optimal configuration of LSC. Olson et al. [11] proposed a 2D/3D methodology to calculate the gain in LSC based on the optical properties of the material. They experimentally investigated the effect of diameter, thickness, and quantum yield using a Rhodamine 6G dye. They suggested the trapping of photons at intermediates steps during the process of absorption and remission. Mcintosh et al. [12] examined the conventional square and novel cylindrical LSC. The latter was found to have higher optical concentration than the former and also proposed that the multi-cylindrical LSC can achieve higher concentration.

Debije et al. [13] examined the scattering effect on LSC efficiency by adding a white scattering layer at the bottom plate. They concluded that the scattering layer separated from the waveguide by an air gap increased energy output. The light output was much higher at a shorter distance of $6 \mathrm{~cm}$; however, got reduced with an increase in distance. Desmet et al. [14] demonstrated the power conversion efficiency of two different sized (5 and $10 \mathrm{~cm}^{2}$ ) LSC. They used Lumogen F Red 305 dye and perylene perinone dye as the waveguide material. The maximum efficiency 
of $4.2 \%$ was observed for $5 \mathrm{~cm}^{2}$ LSC. Mulder et al. [15] discussed the increase in trapping efficiency by using vertically aligned dye molecules and observed an increase of $16 \%$ compared to the no dye alignment in LSC. Debije et al. [16] utilized cholesteric liquid crystals, and with the assistance of the air gap, they tried to reduce the surface losses in LSC and improve the effectiveness of the waveguide. With this setup, the reflection band got redshifted; the air gap resulted in bending of light from a surface of the waveguide. They claimed to have $35 \%$ more light due to the organic fluorescence and increase in power up to $12 \%$. Waveguide material with 1.51 refractive index trapped $75-80 \%$ of light by total internal reflections and the maximum efficiency of LSC is found to be around 7\% [17]. The reasons for lower LSC efficiency were estimated to be due the self-absorption/re-absorption in the luminescent dyes, and escaping of light radiation beyond the critical angle. Wang et al. [18] analyzed LSC coated with europium complex material that can absorb light at a high wavelength (UV region) of the solar spectrum. It is shown that such a coating can be tested for the generation of power, albeit their efficiencies are not much significant. Wittwer et al. [19] used a stack of two plates $(40 \mathrm{~cm} \times 40 \mathrm{~cm} \times 0.3 \mathrm{~cm}$ ), namely a GaAs coupled solar cell and Si coupled solar cell that reported the efficiency of $4 \%$. It is observed that the semiconducting polymers such as red polyfluorene have optical efficiency of $19.8 \%$, which is higher than that of Rhodamine B, which is around 15.3\% [20]. The higher in the efficiency in the former is due to reduced reabsorption losses. Materials are chosen with a higher refractive index in order to have a higher optical clarity in waveguides. The refractive indeed of the materials that are used as waveguide ranges from 1.4 to 1.6 [21]. They found that with an increase in the refractive index, the reflection of light in the visible wavelength also increases. The losses in the LSC are due to the escape of re-emitted light through the top or bottom surfaces of waveguide [22]. In patterned LSC, solar rays are internally reflected if they impinge at an angle greater than the critical angle. In order to limit the number of re-absorption events, patterned waveguides, as shown in Fig. 2 are utilized. The patterned size is varied by the percentage of dye coverage and number of pattern line. Emission efficiency is seen to increase by a reduction in the dye surface area; however, it does not depend upon the dye pattern [23,24]. However, such LSC has lower overall efficiency because of the more blank area [25].

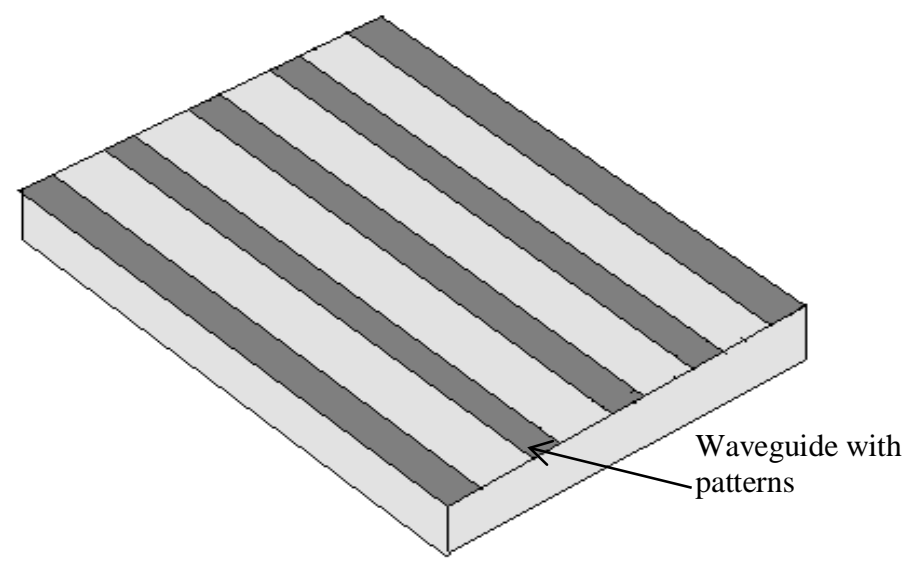

a)

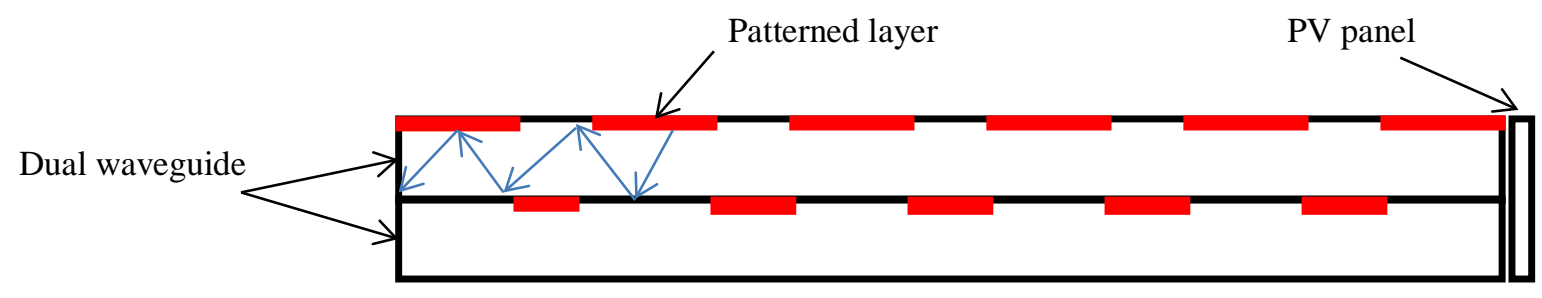

b)

Figure 2. Schematic of the a) single plate pattern and b) dual pattern waveguide 
The Si, GaAs, and GaInP solar cells are more viable for LSC to get more efficiency [2, 5, 26, 27, 28]. The dye coatings with different absorption emission spectrum led to reduced reabsorption loss and increased absorption efficiency. A review article by Hermann [29] describes the operations and development of LSC, the usage of an organic dye, and cost estimates of LSC. Debije and Verbunt [22] presented the review on LSC for the past three decades and focused mainly on the internal losses reduction from LSC using various methods such as coating with luminophores, organic dyes, inorganic phosphors, and quantum dots. Griffini et al. [30] carried out experiments on thin-film LSC, where the effects of dye concentration, LSC film thickness, geometric gain on the LSC performance are investigated. The optical efficiency of LSC is found to be maximum at a dye concentration of $5 \%$ by weight. Higher dye concentration leads to larger re-absorption losses, thus reducing the LSC performance. The LSC optical efficiency is observed to decrease with an increase in the geometric gain due to the increase in the path lengths that the emitted photos have to travel. Zacher et al. [31] carried out experiments on LSC device by increasing the dye concentration, and thereby the self-absorption. They noted that the LSC efficiency depends upon the incident light absorption despite the increase in the dye concentration. Mateen et al. [32] carried out the analyses on LSC with a white scattering layer at the bottom and the cylindrical optical fibers. The arrangement helped in increasing efficiency due to the additional light trapping modes. Rafiee et al. [33] presented a detailed review on the different LSC's, namely, large and small scale, presently used. They described the quality of materials, doping of the concentration materials, geometry, in improving the LSC.

\section{THEORETICAL AND EXPERIMENTAL STUDIES Monte Carlo Simulations}

Monte Carlo (MC) simulations can be utilized to study the propagation of photons in LSC, and such simulations work well for applications where the phase-dependent wave effects are negligible [34-36]. Carracosa et al. [37] performed Monte Carlo simulations on PMMA plate LSC with Rhodamine 6G and Fluorol 555, as the dyes, and found that the multiple-film stack LSC has a better performance compared to the single-film LSC. Figure 3 depicts the MC algorithm that is used in the present study as modelled by Sahin et al. 2011 [34]. A triggered photon in the waveguide is tracked until it reaches the edges or lost through a waveguide. The plate lengths are considered as $L_{x}$ and $L_{y}$ from the center of the plate to the edge, and its thickness is $t$. It is assumed that there are no impurities in a waveguide, and the dye molecules are distributed uniformly throughout the plate. Photon is launched randomly that gets absorbed within the dye's absorption spectrum, and is re-emitted randomly in the waveguide. $1 \times 10^{5}$ photons are used for each incident wavelength to obtain statistically reliable results. PMMA polymer material is used for the waveguide, which has the refractive index of 1.49 and critical angle of $47.8^{\circ}[34,35]$. Dye material used in the present study is perylene Red 305 having the molar mass of $392.32 \mathrm{~g} / \mathrm{mol}$, whose normalized absorption and emissions characteristics can be obtained from Tsoi at al. [24] and Sahin et al. [34].

According to Beer-Lambert law, the probability of a photon being absorbed after being travelled $\Delta s$ distance is given by Eq. 2 as modelled by Sahin et al. 2011 [34].

$$
P=1-10^{-\varepsilon(\lambda) M \Delta s}
$$

where $M$ is a molar concentration of the particles in mol/l, $\varepsilon(\lambda)$ is the extinction coefficient $(\mathrm{l} / \mathrm{mol} . \mathrm{cm})$ obtained from the absorption spectrum [23]. A photon is launched randomly in the waveguide which is sampled randomly from the solar spectrum with wavelength, $\lambda$. The photon is considered to be lost if it is not absorbed within the thickness $(t)$ of the waveguide, and thus, the simulation resumes with a new photon. The random path length of the absorbed photon is calculated by using Eq. 3, where $\xi$ is the random variable, which is uniformly distributed from 0 to 1 [34].

$$
\Delta s=-\frac{1}{\varepsilon(\lambda) M} \log _{10} \xi
$$


Journal of Thermal Engineering, Research Article, Vol. 7, No. 2, Special Issue 13, pp. 240-255, February, 2021

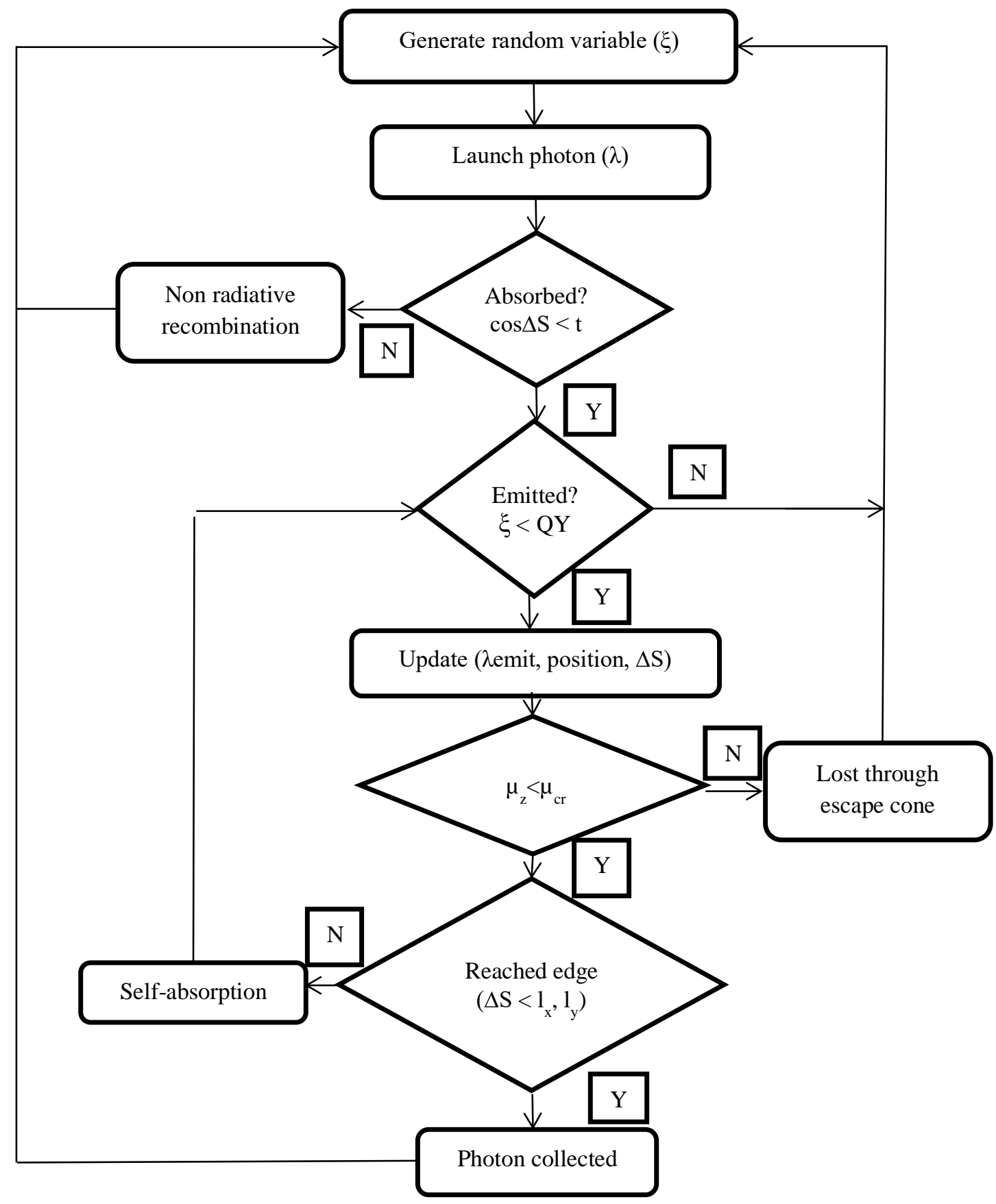

Figure 3. Flowchart of the Monte Carlo simulation algorithm

The absorbed photon is reemitted if $\xi$ is less than the quantum yield of luminescent material [34]. The wavelength of the emitted photon is sampled randomly from the emission spectrum of perylene red dye. The position of the reemitted photon is updated based on its initial position, as given in Eq. 4 [34],

$$
\begin{aligned}
x^{\prime} & =x+\mu_{x} \Delta s \\
y^{\prime} & =y+\mu_{y} \Delta s \\
z^{\prime} & =z+\mu_{z} \Delta s
\end{aligned}
$$


Where, $\mu_{x}, \mu_{y}, \mu_{z}$ are the direction cosines, which are updated accordingly. The azimuthal angle $(\psi(0,2 \pi))$ and zenith angle $(\theta(0, \pi))$ are obtained using Eqs. $5 \& 6$ [34], where $X=2 \xi-1$.

$$
\begin{gathered}
\psi=2 \pi \xi \\
\cos \theta=\operatorname{sign} X-X
\end{gathered}
$$

Further, the direction cosines are updated using the Eq. 7 [34].

$$
\begin{gathered}
\mu_{x}=\sin \theta \cos \psi \\
\mu_{y}=\sin \theta \sin \psi \\
\mu_{z}=\cos \theta
\end{gathered}
$$

The new position $(x, y)$ of a photon is obtained from the initial position $\left(x_{o}, y_{o}\right)$ using the equation of lines in Eqs. 8-10 [34].

$$
\begin{aligned}
& x=x_{o}+\left[\left(\frac{\mu_{x}}{\mu_{z}}\right)\left(z-z_{o}\right)\right] \\
& y=y_{o}+\left[\left(\frac{\mu_{y}}{\mu_{z}}\right)\left(z-z_{o}\right)\right]
\end{aligned}
$$

If $\mu_{x}$ is positive then $z=t$, otherwise, $z=0$. The path travelled (ds) is given in Eq. 10 .

$$
d s=\sqrt{\left(x-x_{o}\right)^{2}+\left(y-y_{o}\right)^{2}+\left(z-z_{o}\right)^{2}}
$$

The simulation continues for the condition, $\Delta s-d s \geq 0$. The new position of re-absorption is obtained, then simulation continues until it reaches the edge of the plate. If the refraction index $(n)$ is greater than unity then waveguide can reflect most of the light back from the top surface by total internal reflection for PMMA. The value of $n_{L S C}$ is assumed to be 1.7, which allows total internal reflection when $\mu_{z}<\mu_{c r}$, where $\mu_{c r}$ is the angle calculated by Snell's law (Eq. 1). The performance parameters of the LSC are calculated using the Eqs. 11-13 [23]. Absolute photon efficiency (APE) of the waveguide is the ratio of the number of photons reached the edge $\left(N_{e}\right)$ of the waveguide to the number of incidence photons $\left(N_{i}\right)$ is given using Eq. 11.

$$
A P E=\frac{N_{e}}{N_{i}}
$$

Relative photon efficiency ( $R P E$ ) or photon-to-photon efficiency is the ratio of a number of photons reaching the edge $\left(N_{e}\right)$ to the number of photons absorbed $\left(N_{a}\right)$ is given using Eq. 12.

$$
R P E=\frac{N_{e}}{N_{a}}
$$

The efficiency of LSC ( $\left.\eta_{L S C}\right)$ is the ratio of power output from LSC to incident radiation which is given in Eq. 13, where $P_{n}$ is the energy of photon at a given wavelength, $\eta_{\text {stokes }}$ and $\eta_{Q Y}$ are the stokes-shift efficiency and quantum yield efficiency, which are taken as 0.75 and 0.95 , respectively [23, 38].

$$
\eta_{L S C}=\frac{\sum_{\lambda=350}^{\lambda=800} P_{n} \times A P E \times \eta_{\text {stokes }} \times \eta_{Q Y}}{\sum_{\lambda=350}^{\lambda=800} P_{n} \times A_{\text {plate }}}
$$




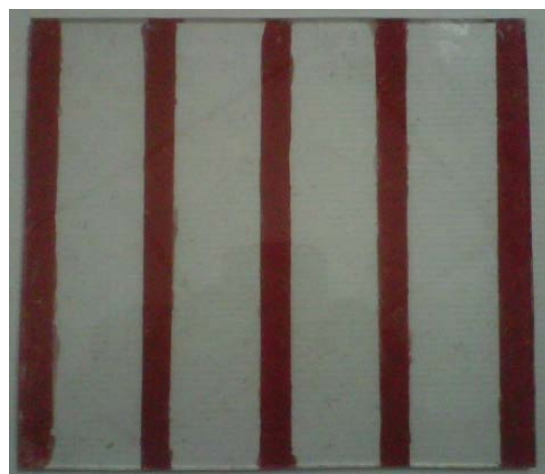

a)

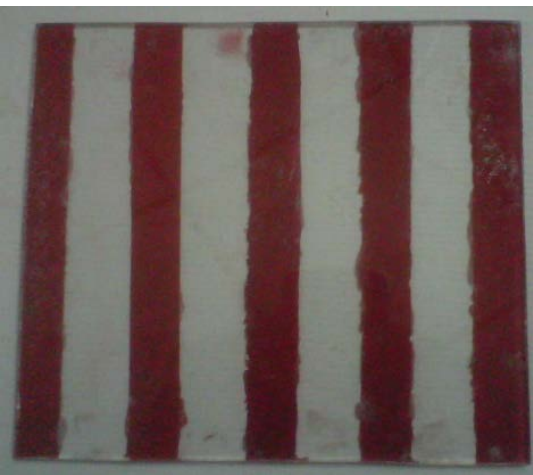

b)

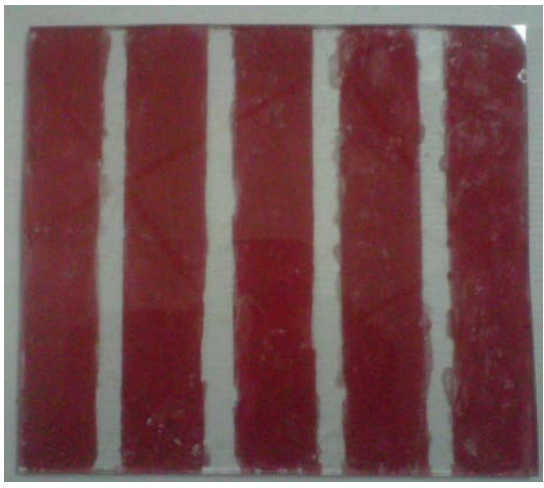

C)

Figure 4. Dye patterned waveguide at a) $30 \%$, b) $50 \%$ and c) $70 \%$ dye coverage area

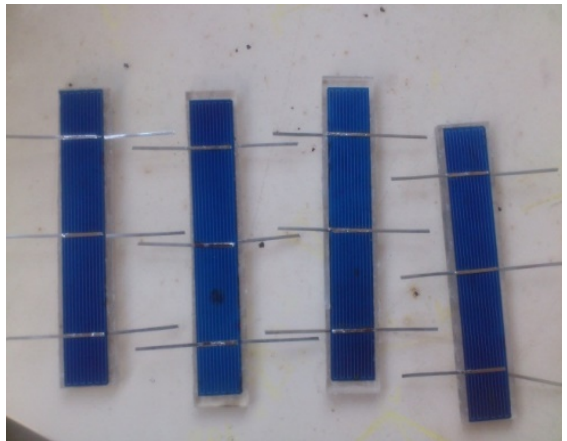

a)

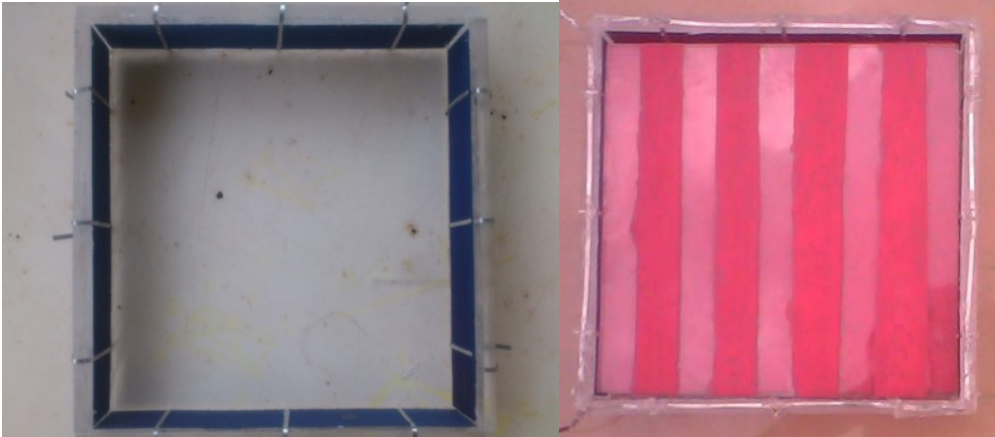

b)

c)

Figure 5. Preparation of LSC waveguide. a) PV cells b) PV cells fixed on sides c) PV cells attached to the waveguide

\section{EXPERIMENTAL METHODOLOGY}

Experiments are carried on a $15 \mathrm{~cm} \times 15 \mathrm{~cm} \times 0.4 \mathrm{~cm}$ PMMA waveguide. The LSC is prepared by coating the perylene red 305 organic dye film on top of waveguides in film patterns. Initially, the organic dye is dissolved in a polymer solution (MMA, Aldrich). The obtained mixture is coated with a thickness of around 100 microns. Plates were prepared for different pattern size, and dye coverage area. Figure 4 shows the waveguides patterned with 30\%, 50\%, and $70 \%$ dye coverage area with five numbers of pattern lines. Solar cells of size $15 \mathrm{~cm} \times 2.5 \mathrm{~cm}$ was mounted along the side of waveguides, as shown in Fig. 5 . The performance parameters of the dual patterned LSC are characterized by calculating fill factor and efficiency of the solar cell. Fill factor $(F F)$ is estimated using Eq. 14 as the ratio of maximum power generated from a solar cell to the product of open-circuit voltage $\left(V_{o c}\right)$ and short-circuit current $\left(I_{s c}\right)$ [39].

$$
F F=\frac{V_{\max } I_{\max }}{V_{o c} I_{s c}}=\frac{P_{\max }}{V_{o c} I_{s c}}
$$

The efficiency of a solar cell is given as the fraction of incident power in the solar cell, which is converted to electricity as given in Eq.15.

$$
\eta_{l s c}=\frac{V_{o c} I_{s c} F F}{P_{i n}}
$$


The errors involved in measurements are $\pm 0.5 \%$ and $\pm 2 \%$ of full scale for voltage and current, respectively. The estimated power has a maximum uncertainty of $\pm 2 \%$. The LSC waveguides are prepared with dye concentrations of $11.33 \times 10^{-3}, 38.65 \times 10^{-3}$ and $58.75 \times 10^{-3} \mathrm{~mol} / \mathrm{l}$. The additional waveguide is placed below the top plate to form a dual waveguide. The LSC performance was analyzed at outdoor under uniform radiation.

\section{RESULTS AND DISCUSSION \\ Effect of Dye Concentration and Waveguide Size}

Initially, the Monte Carlo simulations are carried out for dye-doped LSC under the variable of waveguide size and dye concentration. The square plate size is varied from 10 to $110 \mathrm{~cm}^{2}$, and the concentration of dye is varied from 30 to 800 PPM. The variation of LSC efficiency with dye concentration and waveguide size is plotted in Fig. 6 . The highest efficiency is observed for the lowest size waveguide. A gradual increase in the waveguide size results in a decrease of the LSC efficiency. The figure also indicates that for higher dimension waveguides above $50 \times 50 \mathrm{~cm}^{2}$, the LSC efficiency increases with dye concentration to the maximum value of around 3\% at 200 PPM, and thereafter shows a decreasing trend. For the lower dimensions waveguide, the LSC efficiency is almost constant at higher dye concentrations of above 200 PPM.

\section{Single Waveguide Patterned LSC}

The Monte Carlo simulation for single waveguide LSC (Fig. 2a) is carried out for different dye concentrations of $11.33 \times 10^{-3}, 22.57 \times 10^{-3}, 33.96 \times 10^{-3}, 45.31 \times 10^{-3}, 56.64 \times 10^{-3} \mathrm{~mol} / \mathrm{l}$, and percentage of dye coverage is $100,80,60$, 50, 40 and 20\% with line patterns of 5, 7, 10, 12 and 15. The absolute photon efficiency and relative photon efficiency are obtained for all cases are tabulated in Table 1 . The general observations from the table reveal that the absolute photon efficiency increases with the percentage of dye concentration; however, the relative photon efficiency decreases with the percentage of dye concentration. The case is observed irrespective of a number of patterned lines made in the waveguides. Further, the absolute photon efficiency seems to increase with the dye concentration while the case is not true with the relative photon efficiency. Figure 7 shows the absolute photon efficiency and relative photon efficiency variation with the percentage of dye coverage for various line patterns for the given dye concentration of $11.33 \times 10^{-3} \mathrm{~mol} / \mathrm{l}$. The absolute efficiency is seen to increase with the percentage of dye coverage, thus increasing the overall efficiency of LSC (Fig. 7a). Meanwhile, the increase in the number of pattern line has negligible effects in the absolute efficiencies. However, the relative efficiency decreases with an increase in the percentage of dye coverage, and the highest number of line patterns shows a significant increase in relative photon efficiency (Fig. 7b). In conclusion, it is evident that increasing the patterning of dye almost reduces the overall efficiency, but it increases the waveguide efficiency. The absolute photon efficiency and relative photon efficiency variation with dye concentration is plotted in Fig 8. The graph shows that the absolute efficiency reaches a maximum value at a particular dye concentration and then decreases (Fig. 8a). However, relative efficiency shows a decreasing trend with an increase in dye concentration (Fig. 8b). This is because, an increase in the dye concentration results in increasing the re-absorption loss. There is an optimum dye concentration level where the maximum absolute efficiency is obtained. In this case, the maximum absolute photon efficiency is observed to be $4.5 \%$ at a dye concentration of $0.033 \mathrm{~mol} / \mathrm{l}$. The reduction in absolute efficiency is due to the fact that dye patterning of LSC creates an uncovered area and thus leading to reduced absorption efficiency.

\section{Dual Waveguide Patterned LSC}

Monte Carlo simulations are carried out for the dual waveguide LSC (Fig. 2b) for different dye concentrations of $11.33 \times 10^{-3}, 22.57 \times 10^{-3}, 33.99 \times 10^{-3}$, and $45.31 \times 10^{-3} \mathrm{~mol} / \mathrm{l}$. The percentage of dye coverage area is $80,60,50,40$, and $20 \%$ with 5,10 , and 15 number of pattern lines. The absolute photon efficiency and relative photon efficiency are obtained for all cases are tabulated in Table 2. The variation of absolute and relative photon efficiencies with various dye coverage area is shown in Fig. 9. The figure indicates that the absolute and relative photon efficiencies are highest at $50 \%$ dye coverage. Because the reduced percentage of the dye coverage area of the top waveguide has larger relative photon efficiency than the bottom waveguide, and thus the average relative photon efficiency is less. At $50 \%$ dye coverage area, each waveguide contributes the same amount of loss compared to one with unequal coverage area. Thus at $50 \%$ area coverage, dual patterned waveguide has maximum efficiency as seen in Fig. 9. Figure 10 shows the 
Journal of Thermal Engineering, Research Article, Vol. 7, No. 2, Special Issue 13, pp. 240-255, February, 2021

absolute and relative photon efficiencies variation with dye concentration for the dual waveguide. The maximum absolute photon efficiency is found at a dye concentration of $33.99 \times 10^{-3} \mathrm{~mol} / \mathrm{l}$. However, the relative photon efficiency drops with increase in concentration. This is because, the re-absorption increases with dye concentration, and however, the dye pattern made in LSC reduces the probability of re-absorption. The variation of absolute and relative photon efficiencies with a number of pattern lines for $50 \%$ dye coverage and dye concentration of $33.99 \times 10^{-3} \mathrm{~mol} / \mathrm{l}$ is shown in Fig. 11. These efficiencies increase monotonically, because with an increase in a number of lines, the probability of re-absorption reduces.

Table 1. Simulation results of single waveguide patterned LSC for various dye concentrations, coverage areas, and number of lines

\begin{tabular}{|c|c|c|c|c|c|c|c|c|c|c|c|}
\hline \multicolumn{2}{|c|}{$\begin{array}{c}\text { Dye } \\
\text { concentration } \\
(\mathrm{mol} / \mathrm{l}) \times 10^{-3}\end{array}$} & \multicolumn{2}{|c|}{1.328} & \multicolumn{2}{|c|}{22.657} & \multicolumn{2}{|c|}{33.985} & \multicolumn{2}{|c|}{45.314} & \multicolumn{2}{|c|}{56.643} \\
\hline NL & \%dye & APE & RPE & APE & RPE & APE & RPE & APE & RPE & APE & RPE \\
\hline \multirow{6}{*}{5} & 100 & 3.904 & 33.234 & 4.452 & 31.845 & 4.987 & 28.534 & 4.783 & 28.000 & 4.729 & 27.356 \\
\hline & 80 & 3.643 & 37.833 & 4.124 & 34.010 & 4.725 & 34.430 & 4.254 & 32.321 & 4.354 & 31.024 \\
\hline & 60 & 2.698 & 42.575 & 3.654 & 40.830 & 4.004 & 41.320 & 3.937 & 39. & .634 & 275 \\
\hline & 50 & 2.013 & 54. & 3.012 & 52.8 & 3.673 & 49. & 3.281 & 45.698 & 3.133 & 5 \\
\hline & 40 & 1.973 & & 2.652 & 57. & 2.905 & & 2.801 & & 2.563 & \\
\hline & 20 & 1.492 & 6 & 75 & 6 & 2.401 & 0 & 2.193 & & 2.015 & \\
\hline & 100 & 4.134 & 73 & 4.348 & 31.030 & 4.895 & 28. & 4.701 & & 4.537 & \\
\hline & 80 & 3.423 & 39.284 & 3.934 & 38.234 & 4.623 & 39.320 & 4.352 & 35.453 & 4.234 & 34.236 \\
\hline & 60 & 2.945 & 47.1 & 3.457 & 47.0 & 4.134 & 47 & 3.865 & & 3.342 & 45.720 \\
\hline & 50 & 2.152 & & 2.654 & $54 .{ }^{\circ}$ & 3.329 & 53 & 3.016 & & 3.154 & \\
\hline & 40 & 1.854 & & 2.208 & & 2.803 & & 2.800 & & 2.634 & \\
\hline & 20 & 1.346 & & 1.763 & & 2.201 & & 2.134 & & 2.253 & \\
\hline \multirow{6}{*}{10} & 0 & 4.041 & 32.867 & 4.783 & 31. & 4.934 & 30 & 4.804 & & 4.429 & \\
\hline & 80 & 3.381 & 41.643 & 4.012 & 42.434 & 4.872 & 43. & 4.501 & & 4.132 & \\
\hline & 60 & 3.023 & 49.743 & 3.165 & 47.394 & 4.281 & 46.986 & 4.184 & 42 & 3.812 & 456 \\
\hline & 30 & 2.391 & 56.534 & 2.753 & 56. & 3.382 & 59. & 3.245 & & 3.012 & \\
\hline & 40 & 1.743 & & 2.3 & & 2.983 & & .965 & & 2.734 & \\
\hline & 20 & 1.495 & 69 & 1.875 & 68. & 2.201 & & 1.964 & & 1.634 & \\
\hline \multirow{6}{*}{12} & 100 & 3.825 & 31.643 & 4.674 & 30 & 4.713 & 29 & 4.543 & & 4.517 & 27 \\
\hline & 80 & 3.452 & 45.634 & 3.986 & 45.021 & 4.501 & 44.233 & 4.176 & 35.454 & 4.045 & 32.182 \\
\hline & 60 & 2.465 & 50.734 & 3.234 & 54.237 & 4.103 & 57.234 & 3.754 & 48.454 & 3.622 & 42.222 \\
\hline & 50 & 1.934 & 59.072 & 2.784 & 58.938 & 3.281 & 62.540 & 3.213 & 51.344 & 2.945 & 48.555 \\
\hline & 40 & 1.654 & 65.830 & 2.108 & 65.0 & 2.813 & 64.2 & 2.745 & & 2.542 & 54.345 \\
\hline & 2 & 1.234 & 73.034 & 1.736 & 72.0 & 2.107 & & 2.034 & & 1.900 & \\
\hline \multirow{6}{*}{15} & 100 & 3.954 & 34.542 & 4.764 & 31. & 4.912 & 29.0 & 4.672 & 33 & 4.253 & 29.242 \\
\hline & 80 & 3.563 & 46.743 & 3.764 & 48.142 & 4.723 & 49.322 & 4.357 & 41.234 & 4.145 & 35.342 \\
\hline & 60 & 2.891 & 59.026 & 3.154 & 58.345 & 4.231 & 57.987 & 3.940 & 51.232 & 3.634 & 45.343 \\
\hline & 50 & 2.164 & 69.082 & 2.864 & 68.384 & 3.311 & 69.234 & 3.456 & 61.232 & 3.254 & 52.134 \\
\hline & 40 & 1.814 & 78.028 & 2.356 & 76.384 & 2.743 & 74.321 & 2.684 & 66.173 & 2.734 & 58.234 \\
\hline & 20 & 1.342 & 80.654 & 1.988 & 78.934 & 2.204 & 78.929 & 2.106 & 69.124 & 1.833 & 64.23 \\
\hline
\end{tabular}


Journal of Thermal Engineering, Research Article, Vol. 7, No. 2, Special Issue 13, pp. 240-255, February, 2021

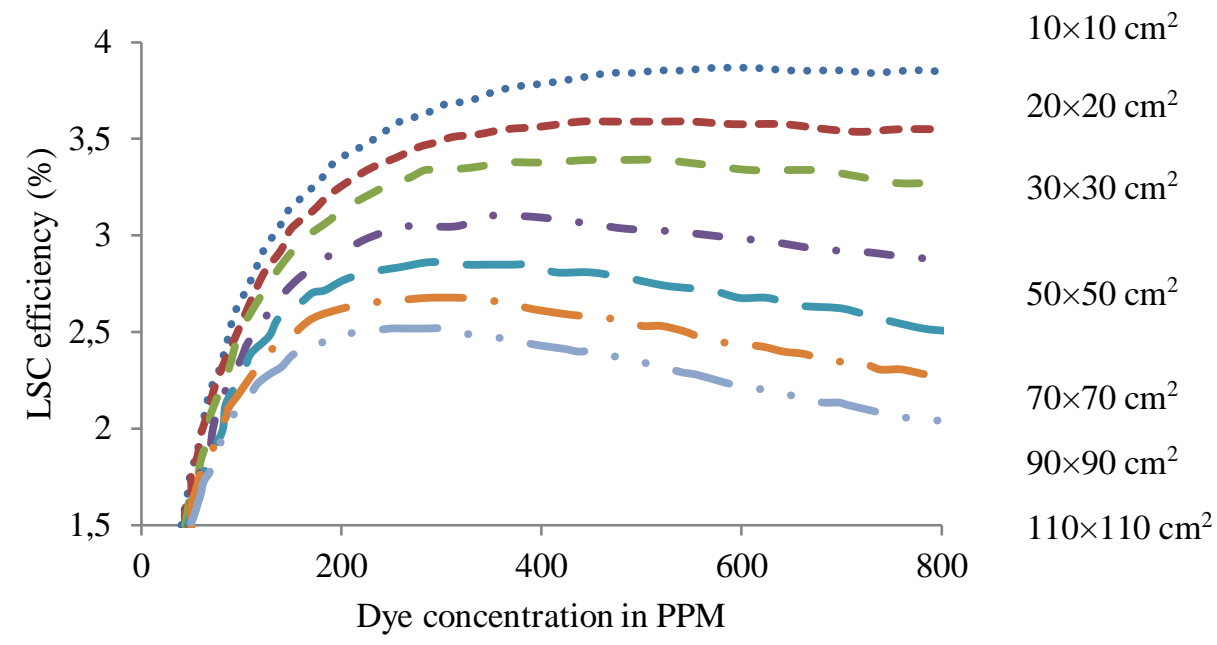

Figure 6. Efficiency of LSC at different dye concentrations and waveguide size

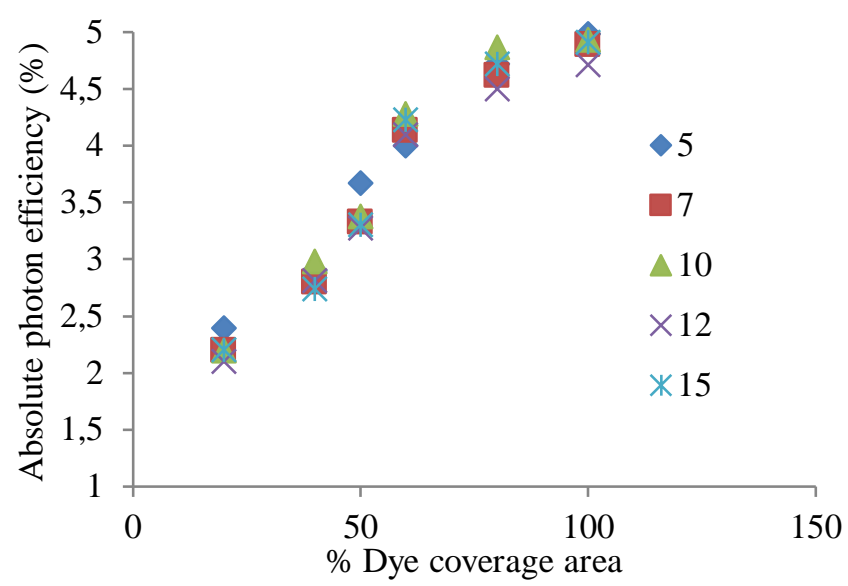

a)

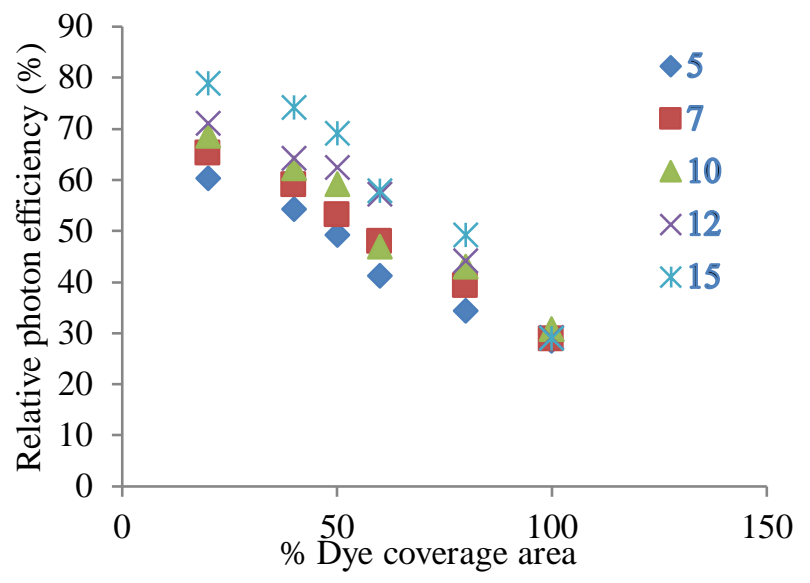

b)

Figure 7. a) Absolute photon efficiency and b) relative photon efficiency of the waveguide with various dye coverage area at a dye concentration of $11.33 \times 10^{-3} \mathrm{~mol} / \mathrm{l}$ for different number of line patterns

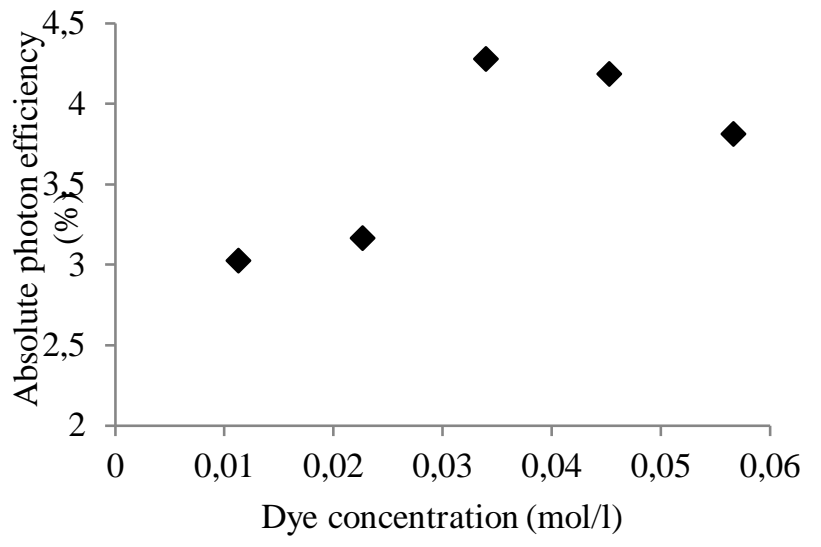

a)

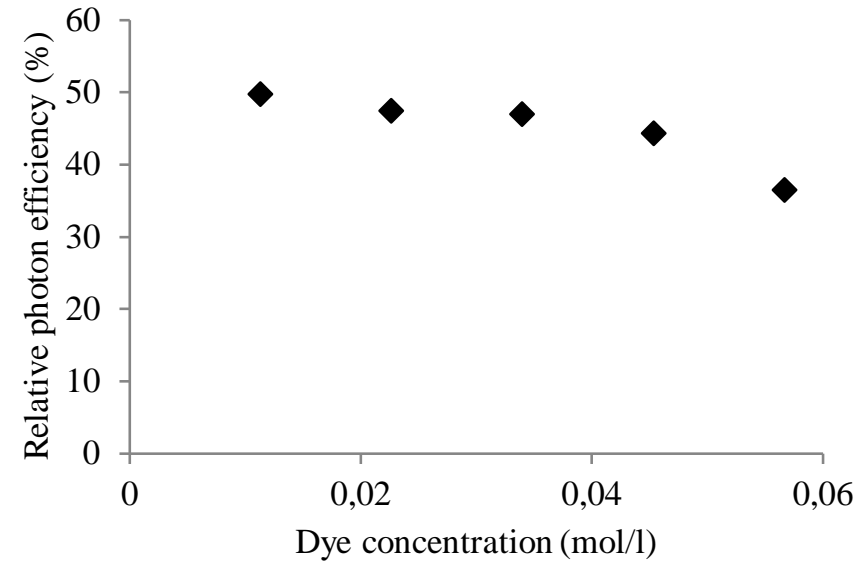

b)

Figure 8. a) Absolute photon efficiency and b) relative photon efficiency of a single waveguide with different dye concentration for $60 \%$ dye coverage area and 5 pattern lines 
Journal of Thermal Engineering, Research Article, Vol. 7, No. 2, Special Issue 13, pp. 240-255, February, 2021

Figure 12 shows the comparison of efficiencies between the single and dual waveguide at a dye concentration of $33.986 \times 10^{-3} \mathrm{~mol} / \mathrm{l}$. The efficiency of single waveguide LSC is seen to increase with \% of dye coverage area, however, the values are much lesser compared to that of dual waveguide LSC (Fig. 12a). An improvement in the absolute efficiency of the dual waveguide is up to $10 \%$ at $50 \%$ dye coverage area. The relative efficiency of single waveguide showed a decreasing trend with \% of dye coverage area, while the values for dual waveguide ranged from 45 to 50\% (Fig. 12b). Thus 50\% dye coverage in patterned layer results in the improvement of both absolute and relative efficiency.

Table 2. Simulation results of dual waveguide patterned LSC for various dye concentrations, coverage areas, and number of lines

\begin{tabular}{|c|c|c|c|c|c|c|c|c|c|c|c|c|c|}
\hline \multicolumn{2}{|c|}{$\begin{array}{c}\text { Dye } \\
\text { Concentration } \\
(\mathrm{mol} / \mathrm{L}) \times 10^{-3} \\
\end{array}$} & \multicolumn{3}{|c|}{11.328} & \multicolumn{3}{|c|}{22.657} & \multicolumn{3}{|c|}{33.985} & \multicolumn{3}{|c|}{45.314} \\
\hline NL & $\begin{array}{c}\% \\
\text { dye }\end{array}$ & APE & RPE & $\eta_{\text {LSC }}$ & APE & RPE & $\eta_{\text {LSC }}$ & APE & RPE & $\eta_{\text {LSC }}$ & APE & RPE & $\eta_{\text {LSC }}$ \\
\hline \multirow{5}{*}{5} & 80 & 7.901 & 48.258 & 5.35 & 8.000 & 47.860 & 6.52 & 8.734 & 47.791 & 6.43 & 8.123 & 46.590 & 5.97 \\
\hline & 60 & 8.400 & 48.789 & 6.02 & 8.343 & 52.857 & 7.47 & 9.433 & 48.235 & 7.84 & 8.974 & 45.907 & 6.95 \\
\hline & 50 & 8.624 & 51.044 & 6.96 & 9.934 & 50.792 & 8.03 & 10.34 & 51.183 & 8.45 & 9.873 & 47.405 & 7.43 \\
\hline & 40 & 8.310 & 49.648 & 6.17 & 9.105 & 48.845 & 7.84 & 9.762 & 48.834 & 8.04 & 8.874 & 45.342 & 6.83 \\
\hline & 20 & 7.756 & 48.118 & 5.02 & 8.483 & 46.979 & 6.23 & 9.074 & 49.346 & 7.31 & 8.194 & 44.488 & 5.88 \\
\hline \multirow{5}{*}{10} & 80 & 7.843 & 49.638 & 5.24 & 8.352 & 56.347 & 7.73 & 8.953 & 55.811 & 6.84 & 8.583 & 48.842 & 6.03 \\
\hline & 60 & 8.365 & 50.083 & 6.24 & 9.392 & 56.325 & 8.40 & 9.753 & 55.848 & 7.46 & 9.643 & 48.837 & 6.75 \\
\hline & 50 & 8.754 & 54.845 & 7.03 & 10.34 & 58.305 & 8.73 & 11.16 & 57.900 & 8.84 & 10.36 & 50.841 & 7.54 \\
\hline & 40 & 8.114 & 52.189 & 6.84 & 9.864 & 53.586 & 8.02 & 10.34 & 56.347 & 7.85 & 9.745 & 50.347 & 7.00 \\
\hline & 20 & 7.845 & 49.943 & 6.08 & 9.037 & 53.790 & 7.54 & 9.624 & 55.909 & 7.06 & 8.127 & 51.383 & 6.43 \\
\hline \multirow{5}{*}{15} & 80 & 7.953 & 62.969 & 5.49 & 8.734 & 64.245 & 6.90 & 9.213 & 64.311 & 6.94 & 8.947 & 57.377 & 6.23 \\
\hline & 60 & 8.262 & 64.440 & 6.02 & 9.897 & 65.091 & 7.84 & 10.23 & 64.109 & 7.32 & 9.423 & 57.931 & 6.90 \\
\hline & 50 & 8.953 & 68.738 & 7.98 & 11.04 & 68.880 & 8.72 & 12.84 & 65.811 & 8.85 & 10.34 & 58.512 & 7.65 \\
\hline & 40 & 8.632 & 66.255 & 7.42 & 10.23 & 63.400 & 7.74 & 11.04 & 67.293 & 7.86 & 10.23 & 58.024 & 6.85 \\
\hline & 20 & 8.105 & 62.860 & 6.02 & 9.582 & 62.390 & 6.94 & 10.76 & 64.664 & 7.09 & 9.632 & 58.906 & 6.34 \\
\hline
\end{tabular}

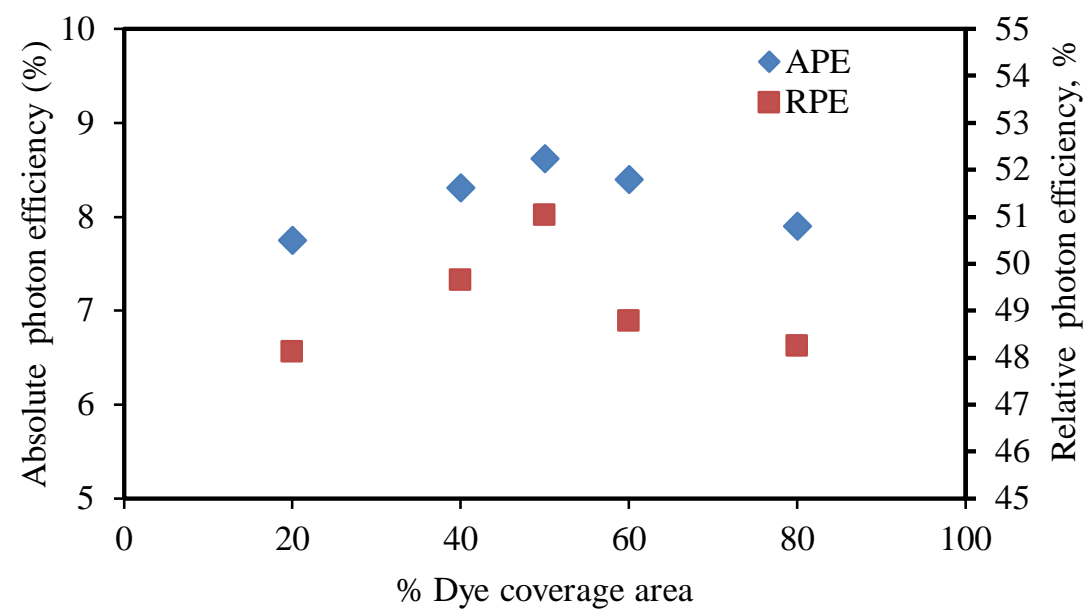

Figure 9. Absolute and relative photon efficiencies variation with dye coverage area for dual waveguide for a dye concentration of $11.33 \times 10^{-3} \mathrm{~mol} / \mathrm{l}$ and 5 pattern lines 
Journal of Thermal Engineering, Research Article, Vol. 7, No. 2, Special Issue 13, pp. 240-255, February, 2021

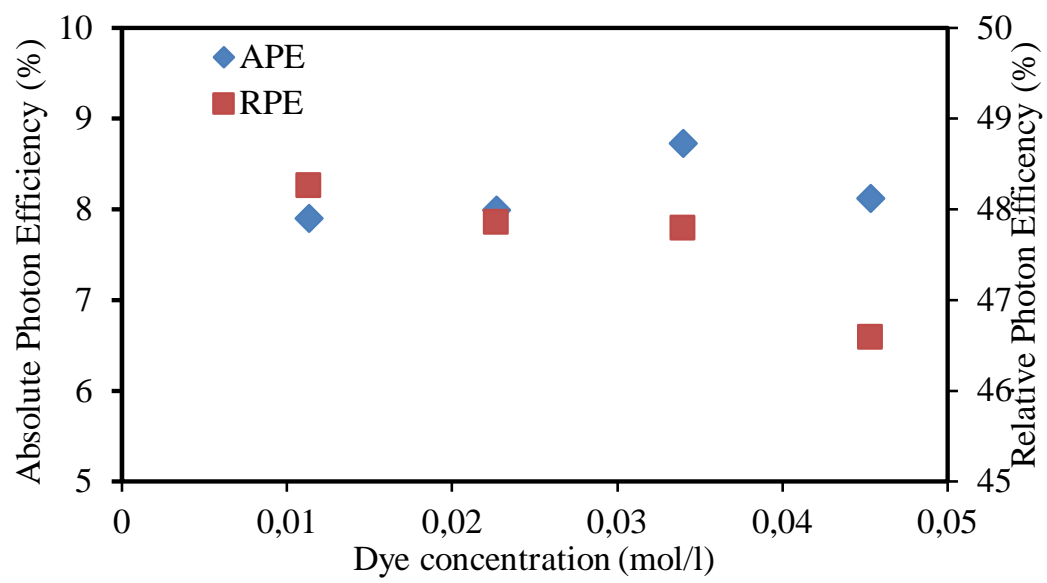

Figure 10. Absolute and relative photon efficiency of the dual waveguide with different dye concentration for $80 \%$ dye coverage area and 5 pattern lines

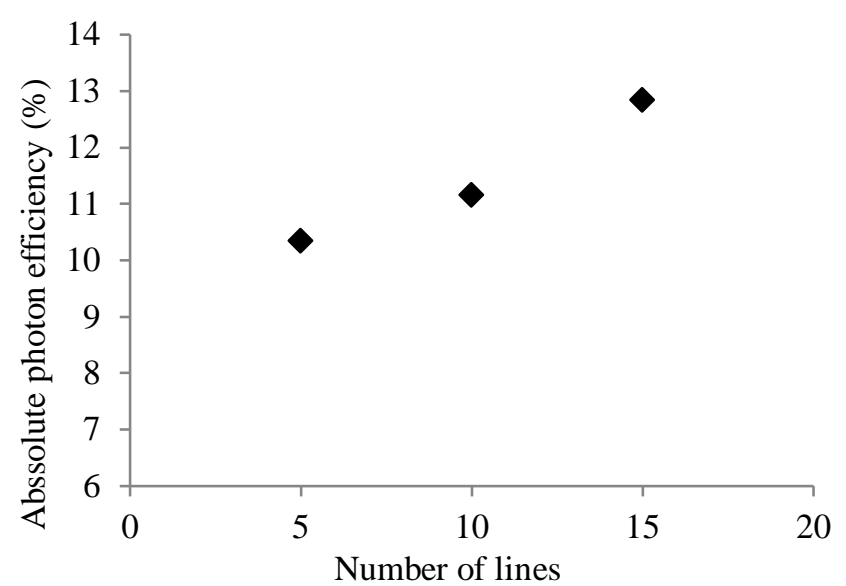

a)

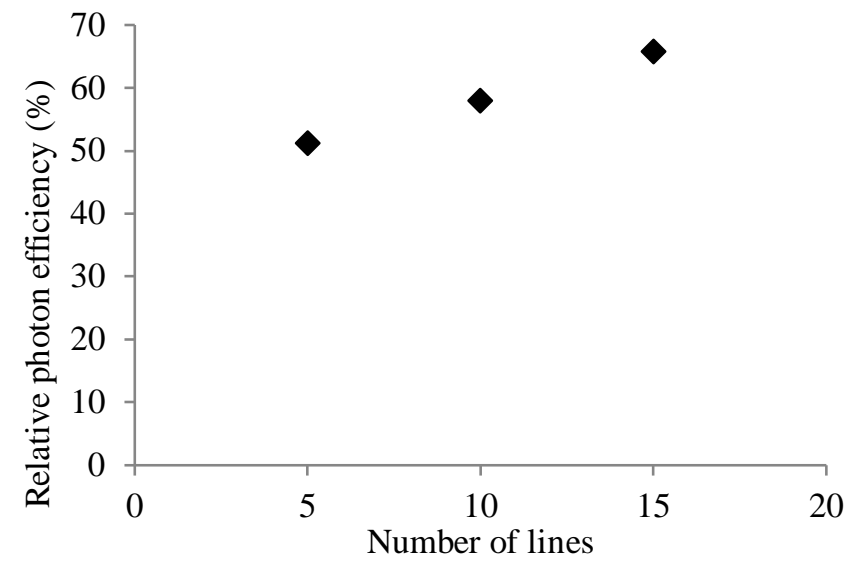

b)

Figure 11. a) Absolute photon efficiency and b) relative photon efficiency of the dual waveguide with a different number of lines for a dye concentration of $33.99 \times 10^{-3} \mathrm{~mol} / \mathrm{l}$ and $50 \%$ dye coverage area

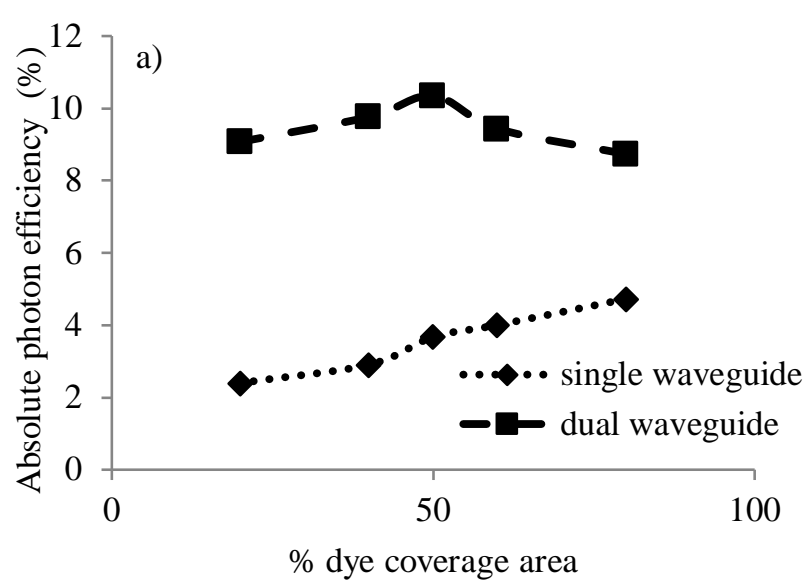

a)

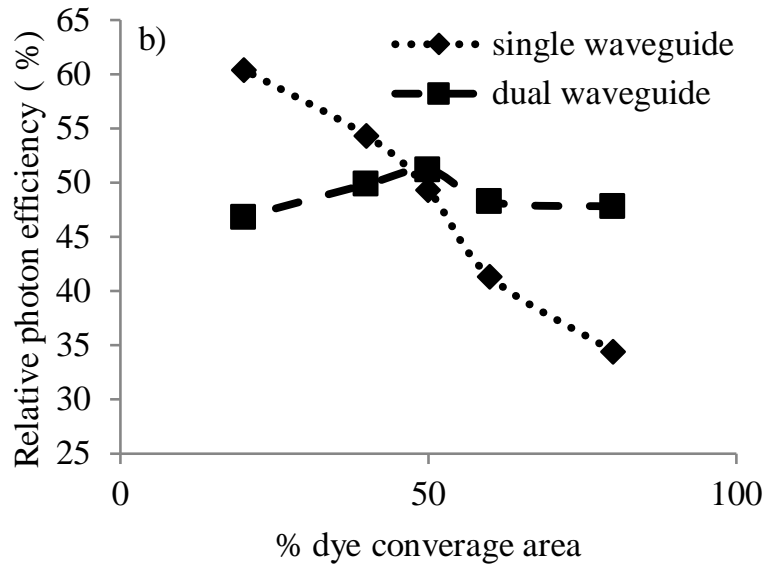

b)

Figure 12. a) Absolute photon efficiency and b) relative photon efficiency comparison of the single and dual waveguide at a dye concentration of $33.99 \times 10^{-3} \mathrm{~mol} / \mathrm{l}$ 


\section{Experimental Results}

Initial experiments were carried out to characterize the PV cell. Under different load conditions, the output current $(I)$ and voltage $(V)$ are tabulated in Table 3, which are used to find maximum power (corresponding to $V_{\max }$ and $I_{\max }$ ). The fill factor for the solar PV cell is estimated to be 0.7 . Experiments were conducted for all dye concentrations at $50 \%$ dye coverage, and results are tabulated in Table 4 . The results show that the LSC efficiency is maximum at a dye concentration of $38.65 \times 10^{-3} \mathrm{~mol} / \mathrm{l}$. Further, maintaining this dye concentration constant, the percentage of area covered is varied, and the results are tabulated in Table 5. Results indicated that the LSC efficiency was lower for $30 \%$ of the area covered, is maximum at $50 \%$ of the area covered, and got decreased at $70 \%$ of area coverage. This is in congruence with the results found in simulation studies. The LSC efficiency variation with the percentage of dye coverage estimated using experiments and simulation is compared in Fig. 13. The experimental data corresponds to dye concentration of $38.65 \times 10^{-3} \mathrm{~mol} / \mathrm{l}$ while the simulation results correspond to $33.98 \times 10^{-3} \mathrm{~mol} / \mathrm{l}$. It is observed from the figure that efficiency gradually increases with the percentage of dye coverage, and peaks at $50 \%$ dye coverage in both the cases and after that starts decreasing. The trend of the simulated and experimental results is observed to be similar. Further, the simulated results over-predict the experimental results due to the variation in the dye concentration in these two cases, and moreover, the dye coating in the experiments was not uniform. The variation of LSC efficiency with dye concentration at 50\% dye coverage area is shown in Fig.14. The trend of the simulated and experimental results is observed to be similar. However, the simulated results over-predict the experimental ones, as observed in Fig. 13. The experimental results also prove that the LSC efficiency increases up to a particular value of dye concentration, and shows a decreasing trend thereafter.

Table 3. Performance of solar PV cell

\begin{tabular}{|c|c|c|c|c|}
\hline $\begin{array}{c}\text { Voltage } \\
(\mathrm{mV})\end{array}$ & $\begin{array}{c}\text { Current } \\
\text { (mA) }\end{array}$ & $\begin{array}{l}\text { Power } \\
(\mathrm{mW})\end{array}$ & $\begin{array}{c}\text { Efficiency } \\
\%\end{array}$ & $\begin{array}{c}\text { Fill } \\
\text { factor }\end{array}$ \\
\hline 631 & 0 & 0 & 0 & \multirow{6}{*}{0.7} \\
\hline 565 & 654 & 369 & 10.6 & \\
\hline 473 & 1289 & 610 & 17.5 & \\
\hline 327 & 1307 & 427 & 12.3 & \\
\hline 189 & 1326 & 251 & 7.2 & \\
\hline 0 & 1453 & 0 & 0 & \\
\hline
\end{tabular}

Table 4. Performance of LSC at various dye concentration for 50\% dye coverage area

\begin{tabular}{|c|c|c|c|c|}
\hline $\begin{array}{c}\text { Dye } \\
\text { concentration } \\
\left(\mathbf{1 0}^{-3} \mathbf{~ m o l} / \mathbf{l}\right)\end{array}$ & $\mathbf{V}_{\mathbf{o c}}(\mathbf{m V})$ & $\mathbf{I}_{\text {sc }} \mathbf{( m A )}$ & $\begin{array}{c}\mathbf{P}_{\max } \\
\mathbf{( m W )}\end{array}$ & $\boldsymbol{\eta}_{\text {LSC }} \mathbf{( \% )}$ \\
\hline 11.33 & 460 & 784 & 361 & 4.4 \\
\hline 38.65 & 456 & 1034 & 472 & 5.7 \\
\hline 58.75 & 458 & 823 & 377 & 5.4 \\
\hline
\end{tabular}

Table 5. Performance of LSC at different dye coverage area for dye concentration of $38.6 \times 10^{-3} \mathrm{~mol} / \mathrm{l}$

\begin{tabular}{|c|c|c|c|c|}
\hline $\begin{array}{c}\text { Dye } \\
\text { coverage } \\
(\mathbf{\%})\end{array}$ & $\mathbf{V}_{\text {oc }}(\mathbf{m V})$ & $\mathbf{I}_{\mathbf{s c}}(\mathbf{m A )}$ & $\mathbf{P}_{\max }(\mathbf{m W})$ & $\boldsymbol{\eta}_{\text {LSC }} \mathbf{( \% )}$ \\
\hline 30 & 429 & 843 & 362 & 4.0 \\
\hline 50 & 437 & 1421 & 621 & 6.2 \\
\hline 70 & 431 & 943 & 406 & 4.4 \\
\hline
\end{tabular}




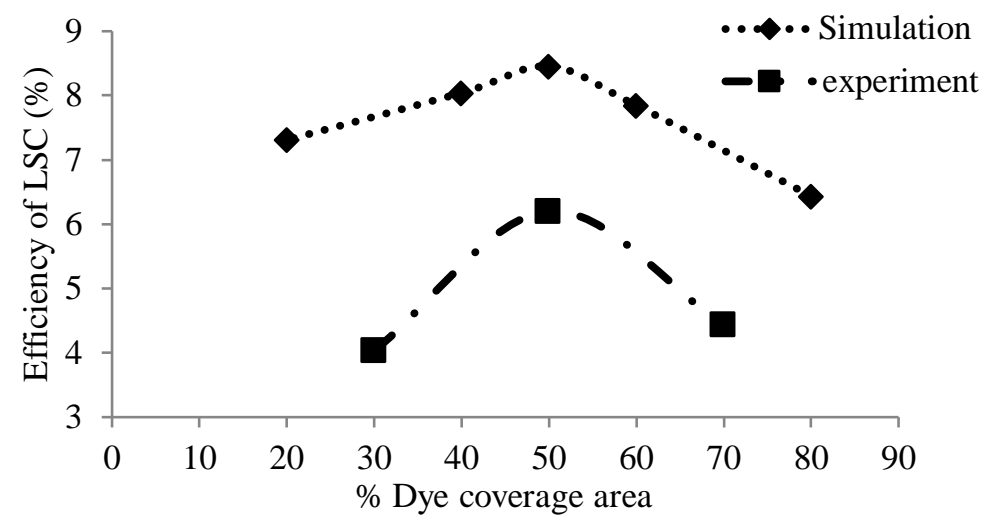

Figure 13. LSC efficiency variation with an area of dye coverage. Simulated results correspond to the concentration of $33.99 \times 10^{-3} \mathrm{~mol} / \mathrm{l}$, and experiment results at a concentration of $38.65 \times 10^{-3} \mathrm{~mol} / \mathrm{l}$

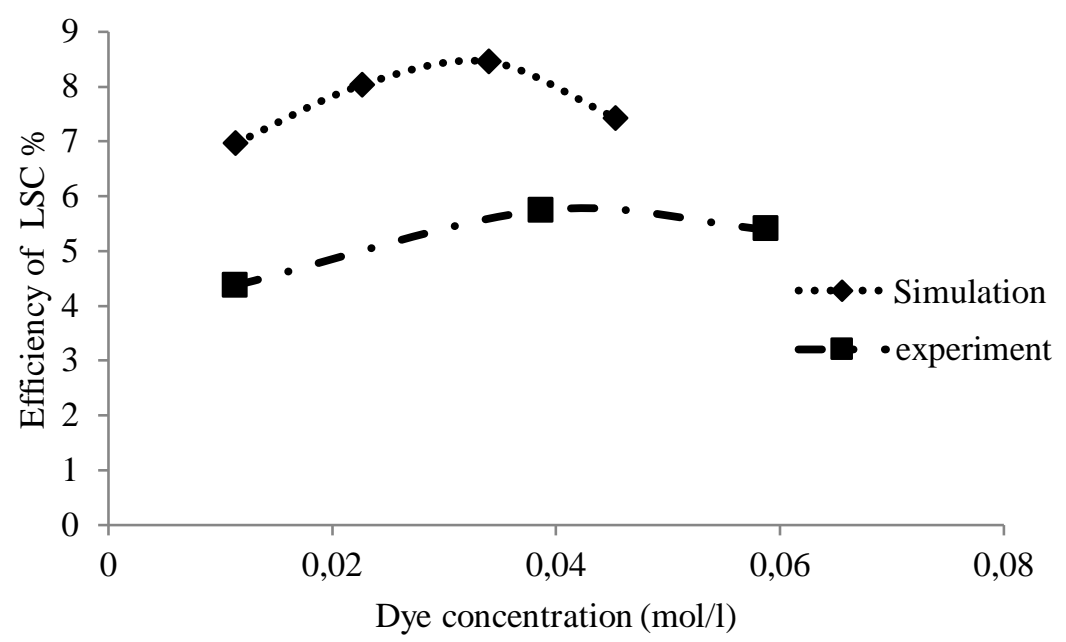

Figure 14. LSC efficiency variation with dye concentration and 50\% dye coverage area

\section{CONCLUSION}

The present paper investigates the luminescent solar concentrator with varied dye concentration and dye coverage area. Simulations are carried out using Monte Carlo Simulations. Dual-patterned waveguides with various dye concentrations and compared with single patterned waveguides. In simulations, the square-shaped waveguides of area varying 10 to $110 \mathrm{~cm}^{2}$ are considered. The dye concentration in the range of 30 to $800 \mathrm{ppm}$ is considered. It is observed that LSC efficiency increases with reduction in waveguides area. Further, LSC efficiency is observed to increase with dye concentration. Analyses carried out for a single waveguide of size $15 \mathrm{~cm} \times 15 \mathrm{~cm} \times 0.4 \mathrm{~cm}$ indicated that the photon transport efficiency has increased while the overall efficiency of LSC decreased. Dual-patterned LSC tested under various dye concentration showed the maximum efficiency at $33.986 \times 10^{-3} \mathrm{~mol} / \mathrm{l}$ and $50 \%$ dye coverage area. LSC showed a monotonic increase in efficiency with an increase in a number of patterns. Experiments are carried out in a dual waveguide LSC coated with different dye concentration, and varied with dye coverage area. Experimental results indicated that the maximum efficiency is obtained at 50\% dye coverage area, which is in congruence with the simulated results. The simulation results gave a maximum LSC efficiency of around $9 \%$ while the value is around $6 \%$ when found experimentally.

\section{ACKNOWLEDGEMENTS}

The earlier version of this work is presented at National Conference on Renewable Energy Innovations for Rural Development, Rural Energy Centre, Gandhigram Rural Institute on 19 March 2014. 
Journal of Thermal Engineering, Research Article, Vol. 7, No. 2, Special Issue 13, pp. 240-255, February, 2021

\section{REFERENCE}

[1] Chow J, Kopp RJ, Portney PR. Energy Resources and Global Development. Science 2003;302:1528-31. DOI: 10.1126/science.1091939.

[2] Batchelder JS, Zewail AH, Cole T. Luminescent solar concentrators. 1: Theory of operation and techniques for performance evaluation. Appl Opt 1979;18: 3090-110. https://doi.org/10.1364/AO.18.003090.

[3] Batchelder JS, Zewail AH, Cole T. Luminescent solar concentrators 2: Experimental and theoretical analysis of their possible efficiencies. Appl Opt 1981;20:3733-54. https://doi.org/10.1364/AO.20.003733.

[4] Friedman PS Luminescent Solar Concentrators. Optical Engineering 1981;20:206887. https://doi.org/10.1117/12.7972831

[5] Slooff LH, Bende EE, Burgers AR, Budel T, Pravettoni M, Kenny RP, Dunlop ED, Büchtemann A. A luminescent solar concentrator with 7.1\% power conversion efficiency. Physica status solidi (RRL) - Rapid Research Letters 2008;2:257-259. https://doi.org/10.1002/pssr.200802186.

[6] Debije MG, Verbunt PPC, Rowan BC, Richards BS, Hoeks TH. Measured surface loss from luminescent solar concentrator waveguides. Appl Opt 2008;47:6763-6768. https://doi.org/10.1364/AO.47.006763.

[7] Vishwanathan B, Reinders AHME, De Boer DKG, Desmet L, Ras AJM, Zahn FH, Debije MG. A comparison of performance of flat and bent photovoltaic luminescent solar concentrators. Solar Energy 2015;112:120 127. https://doi.org/10.1016/j.solener.2014.12.001.

[8] Earp AA, Smith GB, Franklin J, Swift P. Optimization of a three-colour luminescent solar concentrator day lighting system. Solar Energy Materials \& Solar Cells 2004;84: 411-26. DOI: 10.1016/j.solmat.2004.02.046

[9] Earp AA, Smith GB, Swift PD, Franklin J. Maximising the light output of a Luminescent Solar Concentrator. Solar Energy 2004;76:655-67. https://doi.org/10.1016/j.solener.2004.02.001.

[10] Noyola HF, Potterveld DH, Holt RJ, Darling SB. Optimizing luminescent solar concentrator design. Energy and Environmental Science 2012;5:5798-802. https://doi.org/10.1039/C1EE02376D

[11] Olson RW, Loring RF, Fayer MD. Luminescent solar concentrators and the reabsorption problem. Appl Opt 1981;20:2934-40. https://doi.org/10.1364/AO.20.002934

[12] Mcintosh KR, Yamada N, Richards BS. Theoretical comparison of cylindrical and square-planar luminescent solar concentrators. Appl Phys B 2007;88:285-290. https://doi.org/10.1007/s00340-007-2705-8

[13] Debije MG, Teunissen JP, Kastelijn MJ, Verbunt PPC, Bastiaansen CWM. The effect of a scattering layer on the edge output of a luminescent solar concentrator. Sol Energy Mater Sol Cells 2009;93:1345-50. https://doi.org/10.1016/j.solmat.2009.02.013.

[14] Desmet L, Ras AJM, de Boer DKG, Debije MG. Monocrystalline silicon photovoltaic luminescent solar concentrator with 4.2\% power conversion efficiency. Opt Letters 2012;37:3087-89. https://doi.org/10.1364/OL.37.003087.

[15] Mulder CL, Reusswig PD, Velázquez AM, Kim H, Rotschild C, Baldo MA. Dye alignment in luminescent solar concentrators: I. Vertical alignment for improved waveguide coupling. Opt Express 2010;18:A79-A90. https://doi.org/10.1364/OE.18.000A79.

[16] Debije MG, Van MP, Verbunt PPC, Kastelijn MJ, van der Blom RHL, Broer DJ, Bastiaansen CWM. Effect on the output of a luminescent solar concentrator on application of organic wavelength-selective mirrors. Appl Opt 2010;49:745-51. https://doi.org/10.1364/AO.49.000745

[17] van Sark WGJHM, Barnham KWJ, Slooff LH, Chatten AJ, Büchtemann A, Meyer A, McCormack SJ, Koole R, Farrell DJ, Bose R, Bende EE, Burgers AR, Budel T, Quilitz J, Kennedy M, Meyer T, Donegá CDM, Meijerink A, Vanmaekelbergh D Luminescent Solar Concentrators: a review of recent results. Opt Express 2008; 16:21773-92. https://doi.org/10.1364/OE.16.021773

[18] Wang X, Wang T, Tian X, Wang L, Wu W, Luo Y, Zhang Q. Europium complex doped luminescent solar concentrators with extended absorption range from UV to visible region. Sol Energy 2011;85:2179-84. https://doi.org/10.1016/j.solener.2011.06.007

[19] Wittwer V, Stahl W, Goetzberger A. Fluorescent planar concentrators. Sol Energy Mater Sol Cells 1984;11:187-97. https://doi.org/10.1016/0165-1633(84)90070-4

[20] Sholin V, Olson JD, Carter SA. Semiconducting polymers and quantum dots in luminescent solar concentrators for solar energy harvesting. J Appl Phys 2007;101:123114-123114. https://doi.org/10.1063/1.2748350

[21] Kastelijn MJ, Bastiaansen CWM, Debije MG. Influence of waveguide material on light emission in luminescent solar concentrators. Optical Materials 2009;31:1720-22. https://doi.org/10.1016/j.optmat.2009.05.003

[22] Debije MG, Verbunt PPC. Thirty Years of Luminescent Solar Concentrator Research: Solar Energy for the Built Environment. Advanced Energy Materials 2012;2:12-35. https://doi.org/10.1002/aenm.201100554 
[23] Tsoi, S. Structured luminescent solar energy concentrators: a new route towards inexpensive photovoltaic energy Eindhoven: Technische Universiteit Eindhoven 2012. https://doi.org/10.6100/IR724488

[24] Tsoi S, Broer DJ, Bastiaansen CWM and Debije MG. Patterned dye structure limit reabsorption in luminescent solar concentrators. Opt Express 2010;18:A536-A543. https://doi.org/10.1364/OE.18.00A536

[25] Albers PTM, Bastiaansen CWM, Debije MG. Dual waveguide patterned luminescent solar concentrators. Sol Energy 2013;95:216-23. https://doi.org/10.1016/j.solener.2013.06.014

[26] Gallagher SJ, Norton B, Eames PC. Quantum dot solar concentrators: electrical conversion efficiencies and comparative concentrating factors of fabricated devices. Sol Energy 2007;81:813-21. https://doi.org/10.1016/j.solener.2006.09.011

[27] Goldschmidt JC, Peters M, Bösch A, Helmers H, Dimroth F, Glunz SW, Willeke G. Increasing the efficiency of fluorescent concentrator systems. Sol Energy Mater Sol Cells 2009;93:176-82. https://doi.org/10.1016/j.solmat.2008.09.048

[28] Farrell DJ, van Sark WGJHM, Velthuijsen ST, Schropp REI. Using amorphous silicon solar cells to boost the viability of luminescent solar concentrators. Physica Status Solidi 2010;7:1045-48. https://doi.org/10.1002/pssc.200982866

[29] Hermann AM. Luminescent solar concentrators-A review. Sol Energy 1982;29:323-29. https://doi.org/10.1016/0038-092X(82)90247-X

[30] Griffini G, Levi M, Turri S. Thin-film luminescent solar concentrators: A device study towards rational design. Renew Energy 2015;78:288-94. https://doi.org/10.1016/j.renene.2015.01.009

[31] Krumer Z, van Sark WGJHM, Schropp REI, Donegá CDM. Compensation of self-absorption losses in luminescent solar concentrators by increasing luminophore concentration. Sol Energy Mater Sol Cells 2017;167:133-39. https://doi.org/10.1016/j.solmat.2017.04.010

[32] Mateen F, Oh H, Kang J, Lee SY, Hong SK. Improvement in the performance of luminescent solar concentrator using array of cylindrical optical fibers. Renew Energy 2019;138:691-96. https://doi.org/10.1016/j.renene.2019.02.021

[33] Rafiee M, Chandra S, Ahmed H, McCormack SJ. An overview of various configurations of Luminescent Solar Concentrators for photovoltaic applications. Optical Materials 2019;91:212-27. https://doi.org/10.1016/j.optmat.2019.01.007

[34] Sahin D, Ilan B, Kelley DF. Monte-Carlo simulations of light propagation in luminescent solar concentrators based on semiconductor nanoparticles. J App Phys 2011;110:033108. https://doi.org/10.1063/1.3619809

[35] Burgers AR, Slooff LH, Kinderman R, van Roosmalen JAM. Modeling of luminescent concentrators by raytracing. Proc. 20 ${ }^{\text {th }}$ European Photovoltaic Sol Energy Conf. 2005, p. 394-7.

[36] Leow SW, Corrado C, Osborn M, Isaacson M, Alers G, Carter SA. Analyzing luminescent solar concentrators with front-facing photovoltaic cells using weighted Monte Carlo ray tracing. J App Phys 2013;113:214510.

[37] Carrascosa M, Unamuno S, Agullo-Lopez F. Monte Carlo simulation of the performance of PMMA luminescent solar collectors. App Opt 1983; 22: 3236-41. https://doi.org/10.1364/AO.22.003236

[38] Green AP. Optical Properties of Luminescent Solar Concentrators: PhD Thesis. The University of Sheffield, England. 2014

[39] Green MA. Solar cell fill factors: General graph and empirical expressions. Solid State Electronics 1981;24:788 - 89. https://doi.org/10.1016/0038-1101(81)90062-9 